\title{
Joias de crioula - outras inserções em circuitos ideológicos \\ (ou mais sobre a brasilidade da arte brasileira)
}

Renato Rezende*

RESUMO: Este artigo explora a ideia de uma especificidade da arte brasileira ao comparar a produção das joias de crioula na sociedade escravagista brasileira com as Inserções em Circuitos Ideológicos, trabalho dos anos 1970 de Cildo Meireles que circulou durante a ditadura civil-militar brasileira.

PALAVRAS CHAVE: arte brasileira, arte brasileira do século XIX, arte contemporânea brasileira.

ABSTRACT: This article explores the idea of a specificity of Brazilian art by comparing the production of joias de crioula (jewelry used by Brazilian slaves) in the 19th century Brazilian society to Cildo Meireles' work Insertion into Ideological Circuits, produced during the military dictatorship in Brazil during the 1970's.

KEYWORDS: Brazilian art, 19th Century Brazilian art, Contemporary Brazilian art

\footnotetext{
*Renato Rezende é doutorando do Instituto de Artes da UERJ. Autor de Coletivos (com Felipe Scovino, 2010), No contemporâneo: arte e escritura expandidas (com Roberto Corrêa dos Santos, 2011), Experiência e arte contemporânea (com Ana Kiffer, 2012), Conversas com curadores e críticos de arte (com Guilherme Bueno, 2013), Poesia brasileira contemporânea - crítica e política (2014) e Flávio de Carvalho (com Ana Maria Maia, 2015), entre outros.
} 
Um dos mais citados e fecundos filósofos contemporâneos, conhecido tanto por seus estudos da estética como da política (distinção, aliás, que, entre outras - como entre a ética, a lógica e a ontologia -, ele procura apagar) o italiano Giorgio Agamben ${ }^{1}$ abre um texto curto e célebre (na verdade, o início de um seminário), denominado justamente "O que é o contemporâneo?", com as perguntas: "De quem e do quê somos contemporâneos? E, sobretudo, o que significa ser contemporâneo?", para, em seguida, definir a contemporaneidade como "uma singular relação com o próprio tempo, que adere a este e, ao mesmo tempo, toma distância dele; mais precisamente, ela é aquela relação com o tempo que adere a este através de uma defasagem e de um anacronismo."2 Para Agamben, ao forçar uma relação especial entre os tempos, ao insistir no ponto de fratura entre presente e passado (e talvez também futuro), o contemporâneo faz emergir, revitalizado, aquilo que havia sido declarado morto. Não por acaso, Danto, por outras vias, em seu Depois do fim da arte - a arte contemporânea e os limites da história, afirma que, com o término de um tipo de narrativa sobre a arte, que havia se iniciado na Renascença e era pautada pela estética e por noções de estilos e movimentos que progrediam de forma evolutiva, já não haveria mais um critério possível que determine o que é e o que não é arte: todas as formas de mediums e estilos são legítimos. Isso significa que o artista contemporâneo, ao construir sua poética, tem à sua disposição não apenas as novas tecnologias, mas toda a arte do passado (tenha sido ela reconhecida ou não) e seus meios e estilos (com exceção do espírito em que esta arte foi realizada). ${ }^{3}$ Evidentemente, como o próprio Agamben reconhece em seu ensaio, tais noções de história são devedoras, por exemplo, das pesquisas de Foucault sobre o passado ("sombra produzida pela interrogação teórica do presente") e de Benjamin, "quando escrevia que o índice histórico contido nas imagens do passado mostra que essas alcançarão a legibilidade apenas em um determinado momento da sua história".4

Podemos supor, portanto, que o contemporâneo reescreve o passado através do presente, e que compreende o presente através de certa leitura do passado; ou que, em outras palavras, é sempre a partir do presente que se escreve a história da arte. Explícitas se tornam, sob essa perspectiva, as relações entre ideologia e arte, ou as implicações da estética com a política, a estrutura social e a forma como as pessoas experimentam a si mesmas e o mundo. Dessa forma, o crítico literário marxista Terry Eagleton pode afirmar: "Meu pensamento, latu sensu, é de que a categoria do estético assume tal importância no pensamento moderno europeu porque falando de arte ela fala também dessas outras questões, que se encontram no centro 
da luta da classe média pela hegemonia política. A construção da noção moderna do estético é assim inseparável da construção das formas ideológicas dominantes da sociedade de classes moderna, e na verdade, de todo um novo formato da subjetividade apropriado a esta ordem social".5 Para Jacques Rancière, existe na base da política uma estética que determina maneiras de estar em comunidade, que aponta aqueles que têm competência para enunciar, que determina o teor da experiência dos espaços e dos tempos: "É a partir dessa estética primeira que se pode colocar a questão das práticas estéticas, no sentido em que entendemos... como formas de visibilidade das práticas da arte, do lugar que ocupam, do que fazem no que diz respeito ao comum. As práticas estéticas são maneiras de fazer que intervém na distribuição geral das maneiras de fazer e nas relações com maneiras de ser e formas de visibilidade."6 No entanto, não é fácil enxergar com clareza (para Agamben, "contemporâneo é aquele que mantém fixo o olhar no seu tempo, para perceber não as luzes, mas o escuro") ${ }^{7}$ a extensão dos laços viscerais entre os sistemas de pensamento, percepção e desejo inerentes a obras de arte e a ideologia dominante. Há algum tempo muito tem se discutido sobre a passagem da modernidade para um momento pós-moderno, ou contemporâneo, difícil de ser precisamente definido em termos positivos, mas cujas manifestações nos campos do comportamento, da economia, da política e da estética são inegáveis. Seja queiramos identificar o marco histórico do contemporâneo no fim da Segunda Guerra Mundial (como eu sugiro), em maio de 1968, na queda do muro de Berlim ou no atentado às Torres Gêmeas em 11 de setembro de 2001; seja queiramos defini-lo em termos políticos (movimentos anti-partidários e de democracia direta, a globalização e a emergência de potências periféricas), econômicos (a passagem de uma economia de produção para uma de serviços, a intensa especulação e fluxo de capitais) ou estéticos (a superação das vanguardas, a promiscuidade entre gêneros e suportes, o uso paródico da tradição); o fato é que, no seio do próprio capitalismo reificante já não há uma única cultura dominante, e sim culturas; já não há um único discurso, e sim discursos. ${ }^{8}$ Sabemos, por exemplo, como o feminismo e os estudos de uma escrita feminina, os estudos de gêneros e os estudos pós-coloniais, entre outros, desafiaram e deslocaram a centralidade do cânone literário e artístico consagrado pela tradição.

Nesse sentido, no (acelerado) processo de passagem do regime moderno para o contemporâneo, podemos notar claramente um duplo movimento: a fragmentação do discurso único do modernismo internacional e, concomitantemente, a valorização de movimentos artísticos 
locais, principalmente os dos chamados países emergentes (entre os quais se situa o Brasil, com crescente importância geopolítica no cenário global), antes diminuídos como simples reverberações periféricas de manifestos originais gerados pelas vanguardas das metrópoles. No primeiro caso, poderíamos citar uma série de interpretações e releituras do modernismo como um todo e seu desenvolvimento na cultura ocidental, que surgem principalmente a partir do pós-guerra, pulverizando sua genealogia e princípios, estimulando diferentes abordagens, sejam políticas, estéticas ou sociais, e inseridos em distintos contextos geográficos e históricos. ${ }^{9}$ No segundo - de maior interesse para nós neste momento - assistimos a um evidente processo de reavaliação e valorização de artistas e movimentos artísticos brasileiros, sejam eles modernos ou já no vértice do contemporâneo, como é o caso do neoconcretismo; ${ }^{10}$ e ao Brasil (assim como à Argentina, ao México e a outras nações periféricas) é concedido certo protagonismo na narrativa da história da arte. É evidente que tal protagonismo é frequentemente pontual e relativo, ${ }^{11}$ mas - como veremos de forma breve -, seja como for, o caráter original da contribuição brasileira ao universo da arte ocidental, reivindicado principalmente, mas não apenas, por prestigiados intelectuais brasileiros, tende a ganhar corpo e consistência.

Interessante notar que o esfacelamento e a descentralização da narrativa moderna - que um dia pareceu tão sólida ${ }^{12}$ - prosseguem, de forma rizomática e em efeito cascata, em direção aos rincões regionais e ao passado. No campo doméstico, por exemplo, as recentes comemorações dos 90 anos da Semana de Arte Moderna de São Paulo, marco canônico de nosso modernismo, trouxeram à baila um sem número de estudos que contestam e desafiam a hegemonia e a exclusividade do modernismo paulista e seus desenvolvimentos. ${ }^{13} \mathrm{Em}$ âmbito internacional, consolidada a multiplicidade de "modernismos" mais ou menos sincrônicos, a ruína dos discursos monolíticos volta-se ao século imediatamente anterior, o dezenove, ${ }^{14}$ ou mesmo anteriores ou em desalinho com a cronologia e/ou geografia normalmente compreendidas pela história da arte (como podem indicar, por exemplo, algumas das pesquisas de Aby Warburg, que recebem crescente interesse). Rancière, por sua vez, em sua recente obra Aisthesis - scénes du régime esthétique de l'art, propõe uma espécie de contra-história da modernidade artística, ao afirmar que, ao contrário do que acreditávamos, “o movimento próprio do regime estético, aquele que tem sustentado os sonhos de novidade artística e fusão entre arte e vida subtendidos sob a ideia de modernidade, tende a borrar as especificidades das artes e apagar as fronteiras que as separam entre si, ao mesmo tempo em que 
as separam da experiência comum." 15 Seja como for, se a indiscernabilidade entre as artes (e tanto Warburg como Rancière parecem privilegiar a dança ${ }^{16}$ como ação exemplar de tal indiscernabilidade), pelo menos em seu aspecto formal, não for uma prerrogativa do contemporâneo, e sim uma conquista da modernidade (como quer Rancière) ou mesmo anterior a ela (gerada pela relação orgânica - e portanto não-estetizante - entre arte e religião, tal como ainda encontrada em povos não ocidentais, como quer Warburg), tal indiscernabilidade, como é compreendida hoje por algumas vertentes da arte contemporânea (que a utilizam como estratégias de enunciação, ou seja, na costura entre arte e política) a rigor poderia ser identificada em, por exemplo, práticas de subjetivação do espaço social, já no século dezenove (ou antes). Nesses termos, poderíamos pensar as joias de crioula como uma contribuição pioneira e original da arte brasileira - num momento em que a própria noção de arte brasileira não existia, ${ }^{17}$ por ser, como veremos, inautêntica.

Escrevendo para a edição especial da revista inglesa Third Text, dedicada exclusivamente à arte brasileira (implicando, portanto, em sua existência estabelecida) e editada pelo brasileiro Sérgio Bruno Martins, ${ }^{18}$ Rafael Cardoso analisa historicamente os dilemas em torno da questão de uma arte nacional no Brasil de meados do século dezenove até a década de 1930 (ou seja, o segundo modernismo, no contexto do Estado Novo). Ao analisar os discursos produzidos entre o Império e a República, em "The Brazilianness of Brazilian Art," Cardoso cita os então influentes críticos Araújo Porto-Alegre e Gonzaga Duque, para quem "não pode existir uma escola brasileira porque a feição que caracteriza a nossa arte é o cosmopolitismo, e um país para ter uma escola precisa, antes de tudo, de uma arte nacional."19 Interessante notar como tal cosmopolitismo, um eufemismo para mistura de raças, visto de forma negativa e impeditiva no final do século dezenove, torna-se, já no primeiro modernismo, potência (vide Macunaíma, o herói sem nenhum caráter), e desdobra-se, a partir principalmente do final do século vinte, em virtude e especificidade, como atestam, por exemplo, conceitos como "estética da gambiarra".20 Para Cardoso, os discursos dos dois grandes críticos (Porto-Alegre e Duque) encontram-se num único ponto: a arte produzida no Brasil é inautêntica. Ora, o que seria, exatamente, uma arte autêntica? Autêntica seria a arte europeia, erudita, mas em descompasso com as manifestações populares do Novo Mundo; ou autêntica seria a arte popular, gerada pelas tradições indígenas e outras, possivelmente vigorosa, mas inculta e pouco original? ${ }^{21}$ Depois de muitas décadas sofrendo com tais dilemas, talvez possamos afirmar que a arte brasileira tenha resolvido suas angústias de influência e identidade e originalidade ao, no 
momento contemporâneo, tornar positiva a sua negatividade, fazendo da inautenticidade sua mais fecunda contribuição. ${ }^{22}$

O caráter inautêntico, ou melhor, a torção estratégica e subversiva de tal inautenticidade, implicada no uso das joias de crioula ${ }^{23}$ no Brasil escravocrata, bem como no de uma indumentária que incluía o pano da costa e a penca de balangandãs, já foi notado por pesquisadores de diversas áreas, como a história, a antropologia, as ciências sociais e a história da arte, ${ }^{24} \mathrm{O}$ que, por si só, indica o caráter complexo e híbrido, territorialmente difuso e propositadamente hermético, que não se deixa facilmente compreender por uma única abordagem ou disciplina acadêmica, das ações das joias de crioula, que levantam - hoje - a problematização de questões étnicas, religiosas, estéticas, sociais e políticas. Consideradas por Roberto Conduru como "signos de resistência, intercâmbio, invenção e liberdade",25 as joias de crioula, usadas por negras escravas ou alforriadas, burlavam as proibições impostas pela coroa portuguesa aos trajes e ritos permitidos aos segmentos mais baixos da sociedade, e conferiam significados mágicos e religiosos aos materiais e elementos formais que apropriavam dos seus senhores, impregnando-os de camadas subterrâneas de leitura (estéticas, sociais, religiosas) que a estes eram completamente opacos, incompreensíveis. Inseridas no contexto da sociedade colonial e escravocrata brasileira, as joias de crioula, deturpando o significado e o uso de elementos da cultura oficial, geravam fluxos transgressores de sentidos e alteridade, que, aos poucos e no decorrer das décadas, foi impregnando a sociedade brasileira como um todo, não apenas dos aspectos mais evidentes de sua herança, como a indumentária, a decoração (no caso das pencas de balangandãs), o gingado e, em termos mais amplos, de toda a enorme contribuição cultural de origem africana que hoje define o brasileiro, mas também de seus métodos e estratégias de sobrevivência e resistência. ${ }^{26}$ Nesse sentido, na trilha do pensamento aberta por Roberto Conduru, ampliando o campo de percepção da influência das produções afro-brasileiras na nossa arte, são notáveis as semelhanças entre as joias de crioula e alguns trabalhos brasileiros contemporâneos, notadamente algumas ações de Cildo Meireles, que nos autorizariam a falar de uma tradição ou linhagem, cuja identificação e relevância poderiam esclarecer e enriquecer ambas as ações.

Para Guy Brett, crítico de arte inglês que em muito contribuiu no processo de valorização da arte contemporânea brasileira no cenário internacional, Cildo Meireles é um pioneiro. ${ }^{27} \mathrm{O}$ pioneirismo de Cildo - e de outros de sua geração, como Artur Barrio e Antonio Manuel, e 
não apenas no Brasil, mas na América Latina como um todo ${ }^{28}$ - encontra-se em estratégias de deslocamento do objeto de arte e do lugar e função do artista que, em casos exemplares como Inserções em circuitos ideológicos, ${ }^{29}$ respondem de maneira plena e eficaz tanto aos questionamentos formais da arte ocidental de sua época quanto às circunstâncias políticas específicas do Brasil, então sob a repressão de uma ditadura militar. Invertendo o sentido da ideia de ready-made de Duchamp, no qual um objeto do cotidiano é absorvido pelo circuito da arte, na obra de Cildo o objeto de arte atua no cotidiano. Diz o artista sobre essa obra: "Na verdade, as Inserções em circuitos ideológicos nasceram da necessidade de se criar um sistema de circulação, de troca de informações, que não dependesse de nenhum tipo de controle centralizado. Uma língua. Um sistema que, na essência, se opusesse ao da imprensa, do rádio, da televisão, exemplos típicos de media que atingem de fato um público imenso, mas em cujo sistema de circulação está sempre presente um determinado controle e um determinado afunilamento da inserção. Quer dizer, neles a 'inserção' é exercida por uma elite que tem acesso aos níveis em que o sistema se desenvolve: sofisticação tecnológica envolvendo alta soma de dinheiro e/ou poder." 30 Concomitante a esse gesto de intervenção num sistema fechado, o trabalho de Cildo Meireles substitui a noção de mercado ou público pelo de participação, ${ }^{31}$ questionando o conceito de autoria ${ }^{32}$ e tendo como ênfase a memória de uma coletividade, ${ }^{33}$ elementos fundamentais e estruturantes para a eficácia da obra, e que também encontramos, ao praticarmos uma leitura contemporânea do passado, como inerentes ao ambiente instituído pela manufatura e uso das joias de crioula.

O elo que ata no mesmo tempo contemporâneo, ou une na mesma corrente ou colar de tradições, métodos e linguagens, ações/obras apenas aparentemente díspares como as joias de crioula e as Inserções em circuitos ideológicos é ambas terem como medium o próprio corpo social e suas intricadas tramas simbólicas, transgredindo os rígidos estatutos de um circuito que, até recentemente (e aqui podemos identificar o vértice entre modernismo e contemporaneidade) insistia, apesar de fissuras abertas em seu próprio seio, em definir em categorias estanques agentes como artista, público, objeto de arte, mercado, galeria etc. A inespecificidade e abrangência de obras como as joias de crioula e as Inserções em circuitos ideológicos alinham-se com a miscigenação de suportes e a dissolução de fronteiras disciplinares que caracteriza a arte contemporânea como um todo, e lança nossa produção, ainda que inadvertidamente, ao palco principal da história da arte sendo escrita hoje. ${ }^{34}$ Tomando essas duas ações - as joias de crioula e as Inserções em circuitos ideológicos - como paradigmáticas da 
arte brasileira, e como exemplos da trajetória da recepção da arte brasileira e de sua discutida contribuição original - da mais completa invisibilidade a certo protagonismo -, percebemos um longo caminho percorrido desde o cosmopolitismo negativo de Gonzaga Duque até uma paradoxal não especificidade positiva, ápice, talvez, de uma longa discussão sobre o estatuto do objeto na arte brasileira ${ }^{35}$ que, em tempos recentes, passa pelo "não-objeto" (em grande parte um esforço de conclusão, e portanto de fechamento) e pelo "transobjeto" de Hélio Oiticica, no contexto mais amplo de arte ambiental. Concebido a partir de discussões abertas pelo neoconcretismo (movimento do qual Cildo Meireles é reconhecidamente devedor), o conceito de arte ambiental ganha corpo e significância através especialmente dos escritos de Hélio Oiticica e Mário Pedrosa, ${ }^{36}$ mas é Aracy Amaral, em texto de 1981, justamente denominado "Aspectos do não objetualismo no Brasil," quem pela primeira vez enxerga uma possível tradição de arte ambiental no Brasil, por ela identificada como "ações corporais,", que poderia constituir, sempre por vias tortas, a especificidade da contribuição brasileira para a história da arte.

Artigo recebido em julho de 2015 e aprovado em agosto de 2015.

\section{Notas}

1 A coincidência de ele não ser francês nem alemão, mas de outro país europeu e ocidental, secundário na modernidade, quase ponte entre as duas potências pendulares, e de ser referenciado de maneira mais forte tanto por Benjamin e Heidegger como por Foucault e Lacan, não pode deixar de parecer sintomático do momento atual de espraiamento de saberes e poderes.

2 AGAMBEN, Giorgio. "O que é o contemporâneo". In: A vida nua. Tradução de Miguel Serras Pereira. Lisboa: Relógio d'água, 2010. 3 DANTO, Arthur C. After the end of art-contemporary art and the pale of history. Princeton: Princeton University Press, 1997.

4 "É algo do gênero o que devia ter em mente Michel Foucault, quando escrevia que as suas investigações históricas sobre o passado são apenas a sombra produzida pela sua interrogação teórica do presente. "E Walter Benjamin, quando escrevia que o índice histórico contido nas imagens do passado mostra que essas alcançarão a legibilidade apenas em um determinado momento da sua história." AGAMBEN, Giorgio. “O que é o contemporâneo". In: A vida nua. Tradução de Miguel Serras Pereira. Lisboa: Relógio d'água, 2010.

5 EAGLETON, Terry. A ideologia da estética. Tradução de Mauro Sá Rego Costa. Rio de Janeiro: Jorge Zahar, 1993.

6 RANCIÈRE, Jacques. A partilha do sensível - estética e política. Tradução de Mônica Costa Netto. São Paulo: editora $34,2005$.

7 AGAMBEN, Giorgio. "O que é o contemporâneo." In: A vida nua. Tradução de Miguel Serras Pereira. Lisboa: Relógio d’água, 2010.

8 Já em 1923, George Luckás, ao estudar o estatuto do objeto na linha de produção fordista, indica a dupla dinâmica de reificação e fragmentação no seio do capitalismo. Em seu ensaio "The passage of the sign", Hal Foster menciona Luckás ao pensar o desdobramento dessa dinâmica no âmbito das artes visuais na passagem de um regime moderno para um pós-moderno, mencionando o processo de autonomia, descentralização e dissolução do signo. FOSTER, Hal. The return of the real. Cambridge: MIT Press, 1996. 
9 Basta observarmos a miríade de particularidades encontradas nos movimentos modernistas em diversos momentos e espaços pelos mais variados pesquisadores e suas múltiplas nomenclaturas: Jesus Martín-Barbero, modernidade descentrada; Jameson, modernidade singular; Stuart Hall, modernidades alternativas / tardias; Grombrich, modernidade em cascata; Octávio Paz, modernidade transplantada; além das modernidades periféricas, liquidas, paradoxais, etc. É claro que muitos desses termos dizem respeito a abordagens subjetivas ou filosóficas, muito mais que estéticas ou históricas, ou a movimentos pós-modernos, mesmo assim, a mera existência dessa prolixidade é sintomática.

10 O neoconcretismo e o manifesto antropofágico, por exemplo, assim como artistas como Hélio Oiticica, Lygia Pape, Lygia Clark e, mais recentemente, Cildo Meireles, Abraham Palatinik e Flávio de Carvalho têm sido estudados e seus aspectos pioneiros (em âmbito mundial) amplamente reforçados por críticos de arte e intelectuais como Paulo Herkenhoff, Guy Brett e Eduardo Viveiros de Castro, entre outros.

11 Como claramente afirma Michael Asbury, "the arrival of art from the so-called peripherical regions onto the world stage is not principally the result of the intellectual endeavor taken to dismantle the hegemonic powers. Instead, what has ocurred is a significant shift in the world economic and political structure that has allowed this to happen." ASBHURY, Michael "The uroborus effect - Brazilian contemporary art as self-consuming". In: MARTINS, Sérgio Bruno (Ed). Third Text 114, vol. 26, issue 1, janeiro 2012 (Londres).

12 Por narrativa moderna entendo o substrato comum entre os discursos que justificavam uma série de movimentos totalitários nas artes (as inúmeras vanguardas que se levantavam contra o passado e umas contra as outras); na ciência (o cientificismo, a técnica e a produção); na política (o fascismo, o nazismo, o comunismo...), que em diferentes estágios vingaram na Europa e nos EUA a partir da revolução industrial, da guerra de 1812 e das conquistas napoleônicas, até seu trágico colapso no fim da segunda guerra mundial.

13 Pensamos, por exemplo, nas pesquisas de Beatriz Resende sobre a literatura art decô; na polêmica levantada por Paulo Herkenhoff ao defender um fecundo pré-modernismo carioca supostamente sufocado pela narrativa paulista; e o ataque de Luis Augusto Fisher a essa mesma narrativa, em prol de um modernismo literário gaúcho. Historicamente no Brasil, entre muitos estudos, temos, por exemplo, o trabalho de Lafetá, que esclarece a passagem do estético ao ideológico no nosso primeiro e segundo modernismo: Brandão, identificando um modernismo fraco em Minas Gerais; e Viana Moog, já na década de 1940, identificando diversas "ilhas" de modernidade no país

$14 \mathrm{Na}$ introdução de seu livro Art and academics in the nineteenth century, por exemplo, Rafael Cardoso e Colin Trodd explicitam o motivo de sua pesquisa ao estabelecerem as duas principais chaves de leitura da arte do século 19 e indagarem: “Is it possible to generate other readings of academicism and academic institutions since the end of the eighteenth century?" CARDOSO, Rafael Denis, TRODD, Colin (org). Art and academics in the nineteenth century. Manchester: Manchester University Press, 2000

15 RANCIĖRE, Jacques. Aisthesis - Escenas del régimen estético del arte. Tradução de Horacion Pons. Buenos Aires: Manantial, 2013.

16 Se ainda fizer sentido interrogar-se sobre uma arte autenticamente brasileira, tendo em mente as questões que no Brasil historicamente opõem arte popular e arte erudita, talvez encontremos um campo mais fértil e generoso para expressão de nossa alma nacional na música e na dança; e não naquelas manifestações artísticas mais ligadas à intelectualidade europeia, como a literatura e a pintura, gêneros tradicionalmente cultivados e valorizados pela elite e que, diga-se de passagem, entre nós sofrem mais angustiadamente os dilemas de identidade. Para a superação contemporânea desse possível erro de foco, pensemos em Oswald, com sua terrível intuição: "O Carnaval no Rio é o acontecimento religioso da raça". ANDRADE, Oswald de. "O manifesto antropófago". In: MENDONÇA TELES, Gilberto. Vanguarda européia e modernismo brasileiro: apresentação e crítica dos principais manifestos vanguardistas. Petrópolis: Vozes; Brasília: INL, 1976. Ou em Mário Pedrosa, encontrando na escola de samba da Mangueira a mediadora fundamental para o inconformismo absoluto de Hélio Oiticica. PEDROSA, Mário. "Arte ambiental, arte pós-moderna, Hélio Oiticica". In: FERREIRA, Glória. Crítica de arte no Brasil - temáticas contemporâneas. Rio de Janeiro: Funarte, 2006. 
17 Conjeturar sobre quando, onde e sob quais condições sócio-econômicas a História ou, mais especificamente, a História da Arte, se torna uma ciência ou uma disciplina acadêmica está muito distante do escopo deste ensaio. No entanto, podemos facilmente supor, na trilha do raciocínio já mencionado de Eagleton e Rancière (apenas para ficarmos no exemplo dos mesmos pensadores) as implicações políticas e ideológicas de tal gênese e de suas escolhas de objetos. Mencionando o reconhecimento de uma escola espanhola de pintura, que só veio a acontecer no século dezenove, Rancière escreve: "Para que una nueva pintura 'nacional' resultase visible, era preciso que se impusiera la idea del arte como um patrimonio: como la propriedad de un pueblo, la expresión de su forma de vida, pero también como una propriedad compartida cuyas obras pertenencen a ese lugar común que ahora se llama Arte y se concreta en el museo." RANCIÈRE, Jacques. Aisthesis - escenas del régimen estético del arte. Tradução de Horacion Pons. Buenos Aires: Manantial, 2013

18 Em artigo posterior, Sérgio Bruno Martins esclarece com pertinência que "o que há de propriamente revelador na contemporaneidade da arte brasileira é o que sua história nos diz da fonte moderna e, portanto, o que ela é capaz de nos dizer de sua crise. E se ela nos diz algo, é porque não estava simplesmente sentada no banco de reservas, esperando pacientemente uma vaga no time titular da história da arte. Pelo contrário, é por conta de sua relativa marginalidade que se abriram perspectivas críticas diferentes das que se tornaram dominantes no universo da arte contemporânea; elas devem agora ser resgatadas, e não esquecidas". MARTINS, Sergio Bruno. "Por uma recepção extemporânea da arte brasileira". Revista Concinnitas. ANO 2013 - VOL. 1 - N. 20 - agosto 2013 (Rio de Janeiro)

19 DUQUE, Gonzaga. A arte brasileira. Campinas: Mercado de artes, 1995. Apud CARDOSO, Rafael. “The Brazilianness of Brazilian art". In: MARTINS, Sérgio Bruno (Ed). Third Text 114, vol. 26, issue 1, janeiro 2012 (Londres).

20 O glossário de Arte Contemporânea do Itaú Cultural assim define gambiarra: “O termo 'gambiarra' é tipicamente brasileiro e usualmente aplicado para definir improvisação ou desvio de função de determinados aparelhos, objetos e fiações por falta de recursos Geralmente significa uma solução rápida e precária, feita com base no que se tem à mão. O termo passou a ser associado ao universo das artes visuais no Brasil recentemente, com a emergência da produção de artistas que se valem de materiais banais e "pobres", em soluções plásticas que exalam certa precariedade. No que se convenciona referir informalmente como "estética da gambiarra" há alguns elementos quase sempre presentes, como a citada precariedade de meios, o improviso e a inventividade. Outra possibilidade seria a recombinação tecnológica para um novo uso dos materiais. Alguns artistas cuja produção mantém afinidades com a noção de gambiarra: Hélio Oiticica, Marepe, Marcone Moreira, Paulo Nenflidio e Milton Marques". http://novo.itaucultural.org.br/materiacontinuum/marco-abril-2009-arte-contemporanea/. De acordo com Afonso Luz, em conversa com o autor, poderíamos traçar uma genealogia da gambiarra desde a "engenhoca", neologismo forjado no Brasil no séc. 18 supostamente por André João Antonil na obra Cultura e opulência do Brasil por suas drogas e minas.

21 Interessante articular as ideias de Agamben sobre o contemporâneo e sobre o autêntico. Diz ele sobre este último: "A ética começa somente lá onde o bem se revela não consistir em outra coisa senão em uma apreensão do mal, e o autêntico e o próprio, não ter outro conteúdo senão o inautêntico e impróprio." [...] "Até o momento em que, entre os homens, o autêntico e o bem tinham um lugar separado (eram parte), certamente a vida sobre a terra era infinitamente mais bela..." AGAMBEN, Giorgio. A comunidade que vem Tradução de Cláudio Oliveira. Belo Horizonte: Autêntica, 2013.

22 Já em 1975, Mário Pedrosa, apontando para o esgotamento da tradição modernista europeia, escreve que "a história cultural do Terceiro Mundo já não será uma repetição em raccourci da história recente dos Estados Unidos, Alemanha Ocidental, França, etc. [...] A tarefa criativa da humanidade começa a mudar de latitude. [...] Em países como os nossos, que não chegam esgotados, ainda que oprimidos e subdesenvolvidos, no nível da historia contemporânea... quando se diz que sua arte é primitiva ou popular vale tanto quanto dizer que é futurista. [...] Uma arte nova começa a brotar." PEDROSA, Mário. "Discurso aos Tupiniquins ou Nambás". In: FERREIRA, Glória. Crítica de arte no Brasil - temáticas contemporâneas. Rio de Janeiro: Funarte, 2006. Há de se pensar hoje, no entanto, se o sonho de submeter à universalidade do Ocidente a nossa singularidade não caminha para o oposto: nossa suposta singularidade sendo submetida aos princípios do Ocidente moderno antes que nós a realizemos plenamente. Como aponta Eduardo Viveiros de Castro 
numa recente entrevista para a revista Cult: "O Brasil tem a oportunidade única de ser um dos poucos lugares da Terra onde um novo modelo de sociedade e de civilização poderia se constituir. Somos um dos poucos países do mundo que tem recursos suficientes para inventar outra ideia e outra prática de desenvolvimento. Parece que aprendeu muito pouco com a história recente do mundo." SAVIAN FILHO, Juvenal, WILKER, Sousa. "Antropologia renovada" (entrevista). Revista Cult, n. 153, dez. 2010.

23 "Relatos, pinturas e fotografias atestam que joias especiais foram incorporadas aos trajes de algumas mulheres negras, escravas ou livres, durante os séculos XVIII e XIX, na Bahia, situada na Região Nordeste e que abriga a primeira capital do Brasil. Essa singular joalheria é constituída por colares de bolas, colares de alianças ou grilhões, com cruzes, rosetas e outros pingentes, brincos, pulseiras em placas com cilindros, pulseiras de "copo", anéis, pentes, pencas de balangandãs. Foram feitas em ouro ou prata, aos quais, em certos elementos, foram agregados outros materiais preciosos, ou nem tanto: coral, marfim, madeira. [...] Além de sua beleza e raridade, as joias de crioula se distinguem por serem expressões de processos históricos complexos. Elaboradas na Bahia durante os séculos XVIII e XIX, resultam de intercâmbios estabelecidos, no antigo sistema colonial português, entre a metrópole, suas colônias e possessões, nos fluxos econômicos e culturais estabelecidos entre Europa, África e América. A tradição portuguesa de ourivesaria foi mesclada com referências africanas e gerou uma joalheria rara, única." CONDURU, Roberto. "Pérolas da liberdade: joalheria afro-brasileira." In: Textos escolhidos de cultura e arte populares, Rio de Janeiro, v.10, n.1, maio 2013.

24 Entre eles, além do já citado Roberto Conduru, o antropólogo Raul Lody e a historiadora Solange de Sampaio Godoy.

25 “Dos sofrimentos e lutas travadas na escravidão de africanos e de seus descendentes no Brasil, processo que se estendeu entre os séculos XVI e XIX, brotou uma singularidade artística e cultural - a joalheria afro-brasileira: as joias usadas por negras escravizadas ou libertas e os fios de contas usados nas religiões com matrizes africanas. Mais do que expressar riqueza e poder, essas joias são signos de resistência intercâmbio, invenção e liberdade." Ibid.

26 "A vertente artística nomeada como afro-brasileira não tem sido caracterizada como aquela produzida unicamente por afro-descendentes. [...] Além de alguns estrangeiros, artistas das diferentes regiões brasileiras, afro-descendentes ou não, atualizam e ampliam as frentes de ação abertas anteriormente nos diálogos entre arte visuais e afro-brasilidade, respondendo a questões artísticas e culturais contemporâneas." CONDURU, Roberto. "Negrume multicor: arte, África e Brasil para além de raça e etnia". Acervo. Revista do Arquivo Nacional v.22, n.2, 2009.

27 "A tradição do objeto filosófico remonta a Marcel Duchamp e aos dadaístas, e a prática disseminou-se tanto quanto o agora amplo e vago campo conhecido como arte conceitual. Contudo, em relação à prática atual, Cildo deve ser visto como um pioneiro, como um dos pontos de origem do conceitualismo - mesmo que ele não concorde com o rótulo - em virtude do trabalho que ele fazia no Rio de Janeiro em fins dos anos sessenta, quando o Brasil ainda era marginalizado no mundo da arte internacional." BRETT, GUY. "O sensório como forma de conhecimento". In: Brasil experimental: arte/vida: proposições e paradoxos. Tradução de Renato Rezende. Rio de Janeiro: Contracapa, 2005

28 Como demostraram Luis Camnitzer, Jane Farver e Rachel Weiss na exposição "Global Conceptualism: Points of Origin, 1950s-1980s" (MIT List Visual Arts Center. Outubro-dezembro 2000), o surgimento do conceitualismo como nova visão geral da arte e seus circuitos foi mais ou menos simultâneo na Europa Ocidental, nos Estados Unidos, no Japão, na Europa, na Austrália e Nova Zelândia, no Brasil e na Argentina. Mas ao contrário da tendência formalista da arte conceitual norte-americana, os artistas latino-americanos destacaram-se por privilegiar a ação coletiva em relação a processos sociais e políticos. Desse modo, segundo os curadores, a arte de nossos países, assim como as novas sensibilidades e sociabilidades que a expressavam ou das quais era expressão, fundou ao mesmo tempo a des-definição da arte, sua condição experiencial e seu caráter cooperativo. Foi este o modo no qual a arte latino-americana teria colaborado ao processo de globalização das artes, então em fase inicial. CAMNITZER, Luis, FARVER, Jane, WEISS, Rachel. Global Conceptualism: Points of Origin. Cambridge: MIT Press, 2000.

http://listart.mit.edu/node/278\#.UjNq2tl3uSo 
29 Em 1970, Cildo Meireles cria duas Inserções em circuitos ideológicos. No Projeto Coca-Cola, o artista aplica decalques de silk screen em garrafas do refrigerante com os dizeres "Yankees go home!", e logo abaixo: "Inserções em circuitos ideológicos: 1. Projeto Coca-Cola. Gravar nas garrafas opiniões críticas e devolve-las à circulação." Aplicadas na garrafa vazia, as frases são quase invisíveis, mas se tornam legíveis com o líquido dentro. No Projeto Cédula, notas são carimbadas com a frase "Quem matou Herzog?" e devolvidas à circulação.

30 MORAIS, Frederico. "Linguagem material" (entrevista). In: SCOVINO, Felipe (org.) Cildo Meireles. Coleção Encontros. Rio de Janeiro: Azougue, 2009.

31 "No momento em que há distinções nessa ou naquela direção, surge a distinção de quem pode fazer arte e quem não pode fazer. Tal como eu tinha pensado, as Inserções só existiriam na medida em que não fossem mais a obra de uma pessoa. Quer dizer, o trabaIho só existe na medida em que outras pessoas o praticam. Outra coisa que se coloca, então, é a idéia da necessidade do anonimato. A questão do anonimato envolve por extensão a questão da propriedade. Não se trabalharia mais com o objeto, pois o objeto seria uma prática, uma coisa sobre a qual você não poderia ter nenhum tipo de controle ou propriedade. E tentaria colocar outras coisas: primeiro, atingiria mais gente, na medida em que você não precisaria ir até a informação, pois a informação iria até você; e, em decorrência, haveria condições de "explodir" a noção de espaço sagrado." Ibidem.

32 "As Inserções são a negação da autoria, do copyright. Não são obras de arte, mas uma proposta de ação e participação. Tampouco uma forma de arte multiplicada - qualquer nome que se dê a isso: múltiplo, edição, tiragem etc. Eu nunca vendi qualquer de minhas Inserções em circuitos ideológicos." Ibidem.

33 "Pareceu-me que o melhor lugar para uma obra de arte é a memória. Não importa como se chegue a ela. O trabalho de Inserções em circuitos ideológicos se ocupava dessa questão, era uma prática individual em uma escala industrial. [...] acredito que a única possibilidade de permanência de uma obra é a memória. A transitoriedade do tempo não implica na permanência. Esta possibilidade aumenta à medida que a memória se torna mais coletiva. Esse seria seu corolário. Fora disso nos moveríamos no domínio da materialidade, que é um território muito precário. [...] Em relação a Inserções em circuitos ideológicos o que me interessava primeiro era qual seria o objeto que tentasse conciliar esses elementos e ao mesmo tempo em que fosse um objeto com eficácia real, como uma alternativa a comunicação no interior da sociedade, no qual a liberdade individual se mantivesse e não fosse uma coisa discursiva... [...] A questão seria, assim, a necessidade de eficácia social e uma pertinência em relação à história do objeto de arte." ENGUITA, Nuria. "Lugares de divagação" (entrevista). Tradução de Letícia Feres. In: SCOVINO, Felipe (org.) Cildo Meireles. Coleção Encontros. Rio de Janeiro: Azougue, 2009.

34 Ou como disse Eduardo Viveiros de Castro, ferrenho defensor, pelo visada do perspectivismo, da originalidade do Movimento Antropofágico: "Sempre disseram que o Brasil era o país do futuro, iria ser o grande país do futuro. Coisa nenhuma, o futuro é que virou Brasil. O Brasil não chegou ao futuro, foi o contrário. Para o bem ou para o mal, agora tudo é Brasil." CESARINO, Pedro, COHN, Sergio, REZENDE, Renato. "Eduardo Viveiros de Castro" (entrevista). In: CESARINO, Pedro, COHN, Sergio, REZENDE, Renato. Azougue. Rio de Janeiro: Azougue, 2008.

$35 \mathrm{Em}$ uma camada mais profunda, poderíamos propor que as discussões e dilemas sobre uma especificidade e originalidade da arte brasileira, ou seja, sobre a identidade de uma arte nacional, transformaram-se, a partir de Mário Pedrosa, sem que aquela discussão fosse de todo abandonada, em uma problematização sobre o objeto. A questão torna-se explícita desde a tese de Pedrosa sobre gestalt, cuja primeira frase diz que o problema principal da arte é o problema do objeto.

36 Nas palavras de Mário Pedrosa, "arte ambiental é como Oiticica chamou sua arte. Não é com efeito outra coisa. Nela nada é isolado. Não há uma obra que se aprecie em si mesma, como um quadro. O conjunto perceptivo sensorial domina." O artista cria uma "hierarquia de ordens", "todas dirigidas para a criação de um mundo ambiental". "Foi durante a iniciação ao samba que o artista passou da experiência visual, em sua pureza, para uma experiência do tato, do movimento, da fruição sensorial dos materiais, em 
que o corpo inteiro, antes resumido na aristocracia distante do visual, entra como fonte total da sensorialidade." PEDROSA, Mário. "Arte ambiental, arte pós-moderna, Hélio Oiticica". In: FERREIRA, Glória. Crítica de arte no Brasil - temáticas contemporâneas. Rio de Janeiro: Funarte, 2006

37 "Parece frequentemente indefinido no Brasil o limite entre a arte e o folguedo, o poder e a corrupção, o profissional e o amador, o evento social e o artístico... entre colecionador e marchand, arte e exibição, religião e festa, o arrivista e o socialmente inserido, o artista e o pseudoartista. Talvez toda essa ausência de limites se constitua, igualmente, em prova de grande vitalidade, evidência de uma sociedade de mobilidade intensa e fluente. [...] Assim, acreditamos que no Brasil as 'ações corporais' de caráter festivo/coletivo influíram em certas formas expressivas que começam a surgir - ao nível de meio artístico - em meados dos anos 60, por inegável informação internacionalista, aparecendo em particular num artista erudito como Hélio Oiticica." AMARAL, Aracy. "Aspectos do não objetualismo no Brasil." In. AMARAL, Aracy. Arte e meio artístico: entre a feijoada e o x-burger. São Paulo: editora $34,2013$.

\section{Referências}

AGAMBEN, Giorgio. "O que é o contemporâneo". In: A vida nua. Tradução de Miguel Serras Pereira. Lisboa: Relógio d'água, 2010.

A comunidade que vem. Tradução de Cláudio Oliveira. Belo Horizonte: Autêntica, 2013.

AMARAL, Aracy. "Aspectos do não objetualismo no Brasil." In. AMARAL, Aracy. Arte e meio artístico: entre a feijoada e o x-burger. São Paulo: editora 34, 2013.

ANDRADE, Oswald de. "O manifesto antropófago". In: MENDONÇA TELES, Gilberto. Vanguarda européia e modernismo brasileiro: apresentação e crítica dos principais manifestos vanguardistas. Petrópolis: Vozes; Brasília: INL, 1976.

ASBHURY, Michael "The uroborus effect - Brazilian contemporary art as self-consuming". In: MARTINS, Sérgio Bruno (Ed). Third Text 114, vol. 26, issue 1, janeiro 2012 (Londres).

BRANDÃO, Carlos Antônio Leite (Org). As cidades da cidade. Belo Horizonte: Editora UFMG, 2006.

BRETT, GUY. "O sensório como forma de conhecimento". In: Brasil experimental: arte/vida: proposições e paradoxos. Tradução de Renato Rezende. Rio de Janeiro: Contracapa, 2005.

CAMNITZER, Luis, FARVER, Jane, WEISS, Rachel. Global Conceptualism: Points of Origin. Cambridge: MIT Press, 2000.

CARDOSO, Rafael. "The Brazilianness of Brazilian art". In: MARTINS, Sérgio Bruno (Ed). Third Text 114, vol. 26, issue 1, janeiro 2012 (Londres).

TRODD, Colin (Org). Art and academics in the nineteenth century. Manchester: Manchester University Press, 2000

CESARINO, Pedro, COHN, Sergio, REZENDE, Renato. “Eduardo Viveiros de Castro" (entrevista). In: CESARINO, Pedro, COHN, Sergio, REZENDE, Renato. Azougue. Rio de Janeiro: Azougue, 2008.

CONDURU, Roberto. “Negrume multicor: arte, África e Brasil para além de raça e etnia."Acervo. Revista do Arquivo Nacional, v.22, n.2, 2009.

. "Pérolas da liberdade: joalheria afro-brasileira."In: Textos escolhidos de cultura e arte populares, Rio de Janeiro, v.10, n.1, maio 2013. Arte afro-brasileira. Belo Horizonte: Editora C/Arte, 2012

CUNHA, Laura; MILZ, Thomaz. Joias de crioula. São Paulo: Terceiro Nome, 2011.

DANTO, Arthur C. After the end of art - contemporary art and the pale of history. Princeton: Princeton University Press, 1997 
DIDI-HUBERMAN, Georges. A imagem sobrevivente - história da arte e tempo dos fantasmas segundo Aby Warburg. Tradução de Vera Ribeiro. Rio de Janeiro: Contraponto, 2013.

DUQUE, Gonzaga. A arte brasileira. Campinas: Mercado de artes, 1995. Apud CARDOSO, Rafael. "The Brazilianness of Brazilian art". In: MARTINS, Sérgio (Ed). Third Text 114, vol.26, jan. 2012 (Londres).

EAGLETON, Terry. A ideologia da estética. Tradução de Mauro Sá Rego Costa. Rio de Janeiro: Jorge Zahar, 1993.

ENGUITA, Nuria. "Lugares de divagação" (entrevista). Tradução de Letícia Feres. In: SCOVINO, Felipe (org.) Cildo Meireles. Coleção Encontros. Rio de Janeiro: Azougue, 2009.

FERREIRA, Glória. Crítica de arte no Brasil - temáticas contemporâneas. Rio de Janeiro: Funarte, 2006.

FISCHER, Luis Augusto. "Moderno, modernismo, modernista - o peso da semana de arte moderna nos ombros da literatura brasileira". Revista Brasileira. Fase VIII Julho-Ago-Set 2012 Ano I n. 72.

HERKENHOFF, Paulo. Arte Brasileira na Coleção Fadel - da Inquietação do Moderno à Autonomia da Linguagem. Rio de Janeiro: Andrea Jakobsson, 2002.

“Lygia Pape: a arte da passagem". In: PAPE, Lygia. Espaço imantado. São Paulo, Pinacoteca do Estado, 2012.

GODOY, Solange de Sampaio. Círculo de contas: joias de crioulas baianas. Salvador: Fundação Museu Carlos Costa Pinto, 2006.

FOSTER, Hal. The return of the real. Cambridge: MIT Press, 1996.

LAFETÁ, João Luiz. 1930: a crítica e o modernismo. São Paulo: Editora 34, 2000.

LODY, Raul. O que que a bahiana tem: pano-da-costa e roupa de baiana. Rio de Janeiro, FUNARTE, CNFCP, 2003

MARTINS, Sergio Bruno. "Por uma recepção extemporânea da arte brasileira". Revista Concinnitas. ANO 2013 - VOL. 1 - N. 20 - agosto 2013 (Rio de Janeiro).

(Ed). Third Text 114, vol. 26, issue 1, janeiro 2012 (Londres).

MORAIS, Frederico. "Linguagem material" (entrevista). In: SCOVINO, Felipe (Org.) Cildo Meireles. Coleção Encontros. Rio de Janeiro: Azougue, 2009.

MOREIRA, Maria Eunice. "O arquipélago cultural brasileiro: a interpretação de Viana Moog". Revista Letras de Hoje, Porto Alegre, v. 46, n. 4, out./dez. 2011.

PEDROSA, Mário. “Discurso aos Tupiniquins ou Nambás". In: FERREIRA, Glória. Crítica de arte no Brasil - temáticas contemporâneas. Rio de Janeiro: Funarte, 2006.

“Arte ambiental, arte pós-moderna, Hélio Oiticica". In: FERREIRA, Glória. Crítica de arte no Brasil - temáticas contemporâneas. Rio de Janeiro: Funarte, 2006.

RANCIÈRE, Jacques. A partilha do sensível - estética e política. Tradução de Mônica Costa Netto. São Paulo: editora $34,2005$.

Aisthesis - escenas del régimen estético del arte. Tradução de Horacion Pons. Buenos Aires: Manantial, 2013.

RESENDE, Beatriz (Org). Cocaína - Literatura e Outros Companheiros de Ilusão. Rio de Janeiro: Casa da Palavra, 2006.

SCOVINO, Felipe (Org). Cildo Meireles. Coleção Encontros. Rio de Janeiro: Azougue, 2009.

SAVIAN FILHO, Juvenal, WILKER, Sousa. "Antropologia renovada" (entrevista). Revista Cult, n. 153, dez. 2010.

SZTUTMAN, Renato (Org). Eduardo Viveiros de Castro. Coleção Encontros. Rio de Janeiro: Azougue, 2007. 